\title{
Aided Virtual Team Building System: Zooming in on Web 2.0 Tools and Competence Management
}

\author{
Marinita Schumacher ${ }^{1}$, Marc Diviné ${ }^{2}$, Julie Stal-Le Cardinal, \\ and Jean-Claude Bocquet ${ }^{1}$ \\ ${ }^{1}$ Ecole Centrale Paris, Industrial Engineering Department, \\ Grande Voie des Vignes, 92295 Chatenay Malabry Cedex, France \\ \{marinita.schumacher, julie.le-cardinal, jean-claude.bocquet\} @ecp. fr \\ ${ }^{2}$ IAE-Paris, University Paris1 Panthéon-Sorbonne, 21, rue Broca - 75005 Paris, France \\ divine.iae@univ-paris1.fr
}

\begin{abstract}
Our paper responds to the need of an Aided Virtual Team Building System (Aided VTB System). It focuses on virtual teams that are active in virtual design projects in the area of New Product Development (NPD). An extract of requirements of this Aided VTB System is presented that is based on the idea of Quality Function Development and its tool "house of quality". The fulfillment of the demand of the requirements by appropriate relevant and recent concepts and techniques as solutions is discussed with help of a sample survey of 34 virtual team leaders. One of the outcomes of the Aided VTB System is to provide recommendations, guidelines and even best practices to take a choice of web 2.0 tools and concepts and techniques in the domain of competence management.
\end{abstract}

Keywords: Aided VTB System, virtual teams, competence management, web 2.0 tools, sample survey, house of quality.

\section{Introduction}

Even if virtual collaborative environments and platforms are getting more and more popular in various domains such as New Product Development (NPD), R\&D, customer services etc. there is still a weak support of the human dimension for virtual teams $[1,2]$. Empirically-based prescriptions, guidelines and best practices for a system for virtual team building that considers aspects of competence management are often missing. The changing nature of teams and its rising complexity has brought on a need to implement an Aided Virtual Team Building System (Aided VTB System). The Aided VTB System functions as tool kit that features recommendations, guidelines and best practices for virtual team building adapted to the requirements of each specific organization. Many authors have provided their own definition of virtual teams and the concept of virtual team lacks a universally accepted definition $[3,4,5$, 6]. We consider that a virtual team consists of individuals that are geographically and temporally dispersed and act interdependently through technology to achieve a common goal. The purpose is to demonstrate an extract of the Aided VTB System that considers the technical dimension in form of web 2.0 tools and concepts and techniques in the domain of virtual project management as well as the human dimension 
with focus of concepts and techniques in the domain of competence management and virtual team building. In this work we focus especially on concepts and techniques of the domain of web 2.0 tools and competence management.

Secondly, to broaden our results, we present a sample survey that devotes on the part of the web 2.0 tools of the Aided VTB System. It shows the interrelation between four types of value for each web 2.0 tool. These values have been calculated by an extract of the Aided VTB System, its requirements the fulfillment of their demand by concepts and techniques that are considered as most famous virtual team practices in the literature. The sample survey helps us to compare an extract of the results of the Aided VTB System designed with those virtual team practices as described in the literature with the actual use of the tools in the industrial practice. This will help to find out strengths and weaknesses of the extract of existent concepts and techniques due to the demand of the requirements that could be adapted easily to the Aided VTB System. In addition, the Aided VTB System will show correlations between respective concepts and techniques that have a specific rapport among each other. Furthermore, through this approach we get information about those requirements whose demands are not achieved by existent concepts and techniques. We finish in a last step with our concluding remarks and some perspectives for future work. Building on the extract of the Aided VTB System and the comparison with the survey sample makes it possible for us to give guidelines and recommendations for further research to implement a system like ours in industry.

\section{Positioning of the Aided VTB System}

In this work we bring the purpose on virtual design project teams in the domain of NPD. This is why the Aided VTB System has next to the domain of competence management also to consider concepts and techniques of the field of virtual project management, virtual team building and web 2.0. Virtual teams are more complex than traditional teams and have specific characteristics related to the fact that they cross boundaries concerning time, geographical distance and organisations. They use web 2.0 tools to communicate and share information and collaborate to achieve a common goal. The web 2.0 tools are considered as a series of tools which allow interaction between internauts with web sites and other web connected devices [7].

Before presenting the approach of our study we give an overview of the positioning of the Aided VTB System. Due to the systemic approach that we pursued in our previous work $[8,9]$ the domains competence management, virtual project management, virtual team building, and web 2.0 tools are considered as systems that are in interrelation with the Aided VTB System. The Virtual Teams which we handle are active in virtual design projects in the area of NPD. The value of virtual teams in NPD is undeniable. In our work we are considering the virtual aspect in NPD processes that claim other demands than traditional design projects in the domain of project management. The Aided VTB System handles the domain of NPD as context. It is evident, that virtual teams generally face greater project management challenges than traditional face-to-face teams. The aspect of project management is considered as kind of organisation of our work. An overview of the positioning of the Aided VTB System is given in figure 1 . 




Fig. 1. Positioning of the Aided VTB System

Figure 1 highlights that all four systems are integrated as subsystems in the domain of project management that functions as organisation sector and is canopied by the context of the NPD.

To explain the arrows it is to say that the Aided VTB System functions as method that supports the four respective subsystems to create virtual teams by giving best practices, guidelines and recommendations. On the other hand the experience of those four subsystems can enhance the Aided VTB System by giving recommendations. This is important for the functioning of the project management and thereby as well for the NPD.

\section{Approach of Our Study}

In the first step of our study requirements of the presented Aided VTB System are defined and the fulfillment of their demand by appropriate relevant and recent concepts and techniques as solutions discussed on the basis of a graphic tool called house of quality. In the second step we broaden the results gained by the extract of the Aided VTB System with help of a sample survey.

\subsection{House of Quality}

The approach of the house of quality is based on the Quality Function Deployment (QFD) method, which was introduced by Akao [10] in the shipbuilding industry in the 1970s. It has been used successfully for many years as a quality assurance methodology. The house of quality helps to translate customer requirements into a pertinent number of quality characteristics $[10,11]$. In the approach we describe the underlying customer requirements describe the demand of the Aided VTB System. The quality characteristics are in our case detected solutions, concepts and techniques in the domain of competence management (CM), virtual project management (VPM) and virtual team building (VTB), as well as web 2.0 tools (WEB).

The house of quality helps to define not only the relationship between customer requirements describing the Aided VTB System and quality characteristics. It analyses also the correlation between the individual quality characteristics. The basic construction of the house of quality is made up of four major building blocks that compose the form of a house [10]. These include customer requirements, quality characteristics, a relationship matrix, and a correlation matrix. An overview of the basic structure of the house of quality is presented in figure 2 . 


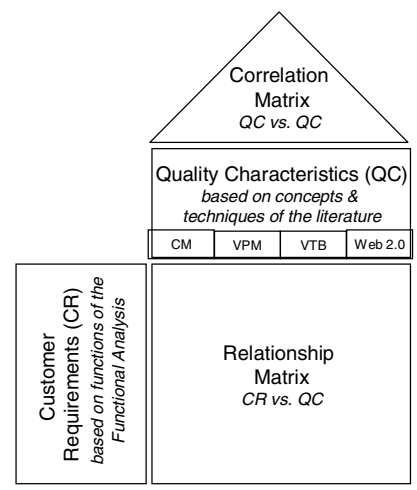

Fig. 2. Scheme of House of Quality due to the Aided VTB System

A table with customer requirements on the left and quality characteristics on the top is shown in figure 2. The roof is composed as diagonal matrix of quality characteristics. The body of the house of quality builds a relationship matrix of customer requirements versus quality characteristics. It helps to draw conclusions in which degree the proposed quality characteristics respond to the demand of the customer requirements.

\subsubsection{Customer Requirements}

The customer requirements are based on the functional analysis that has been performed in our previous work $[4,5]$. The functional analysis is the tool that we use to be as objective, generic and exhaustive as possible [12]. It helps us to understand the complexity of the Aided VTB System from a systemic point of view. It is considered as a system that is described by functions. The functions describe the optimum behavior of the system and its terms of usability. They are considered as customer requirements in the house of quality. The following listing gives two examples of those functions.

FT19 The system should make competencies accessible and useable for organisations.

FC29 The system should allow distance reduction and easy socialization in trustworthy virtual environment.

\subsubsection{Quality Characteristics}

While customer requirements describe what should be implemented, quality characteristics are focused on the way how those requirements should be implemented and give precise recommendations. For reasons of visualisation table 1 shows only a brief extract of the eight quality characteristics due to the domains of competence management and web 2.0 tools that are considered in this study.

\subsection{Sample Survey}

In the second part of our study we compare the theoretical results of the presented extract of the Aided VTB System gained by the approach of house of quality with the industrial reality. With the help of a sample survey based on interviews with 34 participants we aim to provide proposition due to the Aided VTB System. We verify 
Table 1. Quality characteristics due to the domains of competence management and web 2.0

\begin{tabular}{|ll|}
\hline \multicolumn{1}{|c|}{ Competence Management (CM) } \\
\hline CM1 & Access to a global network of experts, providers and partners [13] \\
\hline CM2 & On demand weak to strong ties processes [14] \\
\hline CM3 & People experience and competencies profile data base [14] \\
\hline CM4 & Interdisciplinary teams of excellence consisting of experts from different areas [15] \\
\hline CM5 & Process-oriented human resources planning [16] \\
\hline CM6 & Systematic identification, assessment \& assignment of competence requirements of projects [17] \\
\hline CM7 & Projects' associated competencies ontology [16] \\
\hline CM8 & $\begin{array}{l}\text { Repeatedly analyses of partial tasks to determine changed requirements for competencies during } \\
\text { the process [17] }\end{array}$ \\
\hline WEB1 & $\begin{array}{l}\text { Chat: Instant written conversation area, where the real-time dialog appears line by line as in a } \\
\text { book's people dialog. }\end{array}$ \\
\hline WEB2 & $\begin{array}{l}\text { Forum (Fm): Area opened by a moderator who suggests specific topics and invites members to } \\
\text { post messages and comments. }\end{array}$ \\
\hline WEB3 & $\begin{array}{l}\text { Web Conferencing: Live meeting combining voice on the phone and onscreen presentations by } \\
\text { a speaker. }\end{array}$ \\
\hline WEB4 & Blog: Personal web site where owner post messages and invite people to post comments. \\
\hline WEB5 & \begin{tabular}{l} 
Wiki: Web site which pages can be created and modified by visitors. \\
\hline WEB6
\end{tabular} $\begin{array}{l}\text { Posting \& Sharing (P.S.): Ability given to visitors to upload \& to modify documents located in a } \\
\text { web site area. }\end{array}$ \\
\hline WEB7 & $\begin{array}{l}\text { Commenting, Rating, Polling (C.R.P.): Add a written remark, evaluate content \& survey } \\
\text { participants' opinion with online questionnaires }\end{array}$ \\
\hline WEB8 & $\begin{array}{l}\text { Social Network (S.N.): A site where community members post in a personal area their profile, } \\
\text { photo, interest and links with other persons }\end{array}$ \\
\hline
\end{tabular}

whether the selection of tools deducted from the requirements of the Aided VTB System and the concepts and techniques is the same as the tools in use or the tools best rated in interest. The choice of the interviewees of the sample survey is based on organisations that employ over 5000 employees worldwide. The interviewees work in marketing departments as manager and are involved in virtual teams in mid or long term interdisciplinary NPD projects. They are based in France in order to limit cultural differences. The number of the 34 organisations with over 5000 employees worldwide that intervened can be compared with the number of organisations with over 5000 employees in France that is in total 82. This deduces that the sample survey reaches a very significant proportion of 36\%. Furthermore, out of the 34 organisations, $16.37 \%$ belong to the Stock French Index CAC40.

The interview took about an hour. It was structured in three parts and started with an introduction part about 20 existing web 2.0 tools definitions to get to a common understanding. The second part focused the question if each respective tool was used by the virtual teams in which the interviewees are involved. We considered also the question if other web interaction tools are used apart from the 20 listed. In the third part of the interview the interviewee was asked to evaluate the interest of the use of the tool within the project teams.

\section{Results}

Before going into detail of purposes of our work we present with figure 3 the extract of the house of quality that builds the basis of our results. 


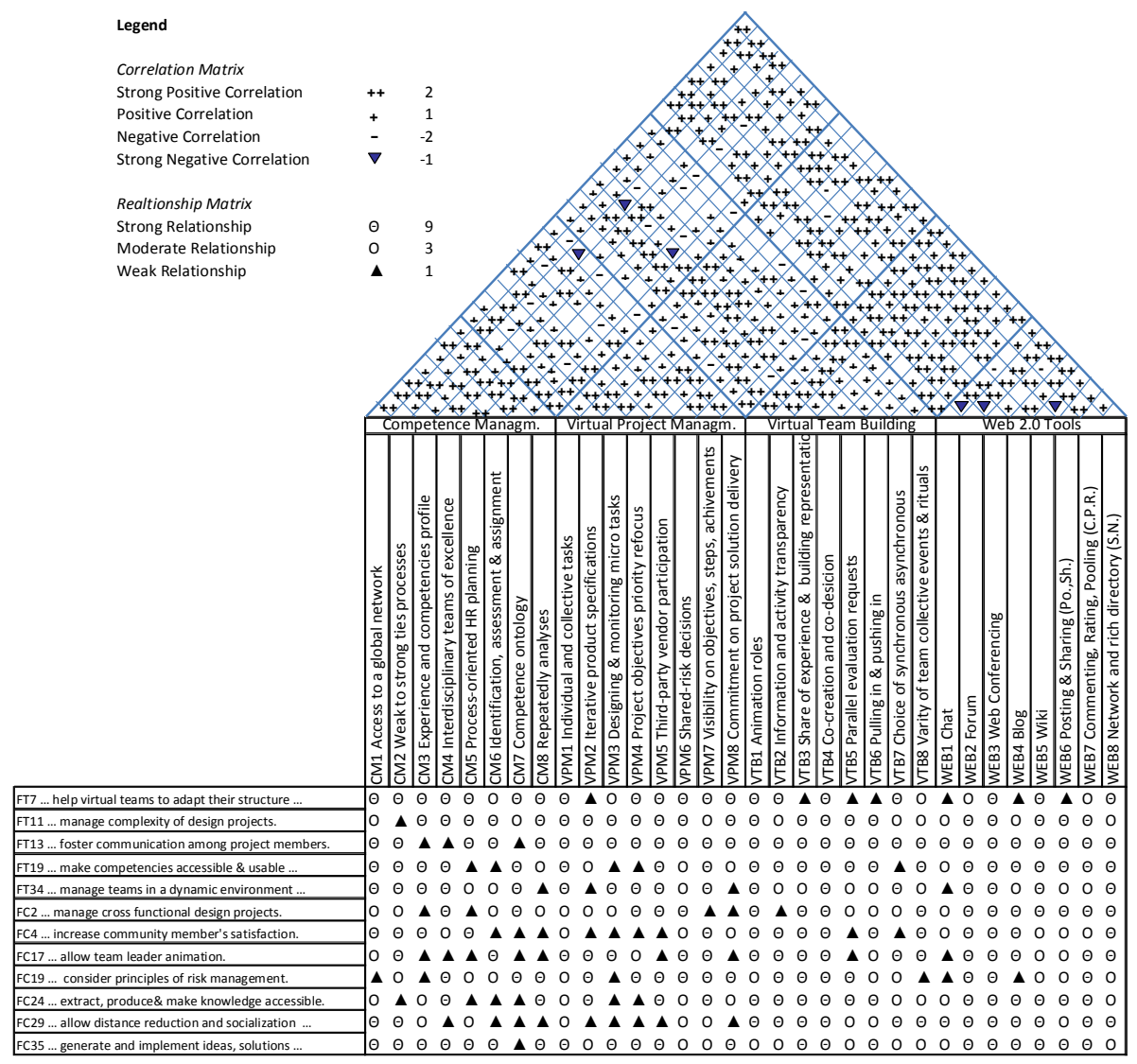

Fig. 3. Extract of the Aided VTB System due to the house of quality

The results of the house of quality are extremely rich and there is much potential of interpretation depending on the respective point of view on the work. In this study we concentrate on two aspects. Our first purpose is set on the functions and represents how well they are satisfied by the extract of 24 quality characteristics as well which quality characteristics in the domain of competence management and web 2.0 satisfied the best most of the functions. The second focus is set exclusively on the web 2.0 tools to put our theoretical results in relation with the sample survey of the industrial practice.

\subsection{Results due to the House of Quality}

By establishing a relation between the customer requirements and the quality characteristics we get information about if concepts and techniques match the demand of the functions and in what degree. The results of the analysis of the relationship matrix are shown in table 2. 
Table 2. Analysis of relationship matrix according to the extract of the Aided VTB System

\begin{tabular}{|c|c|c|c|c|c|c|}
\hline \multirow{2}{*}{\begin{tabular}{|l|} 
Customer Requirements \\
The system should... \\
FT7 ... help virtual teams to adapt their structure to the \\
objectives to the requirements by agility.
\end{tabular}} & \multicolumn{2}{|c|}{$\begin{array}{l}\text { QC: all } \\
\text { Total Index }\end{array}$} & \multicolumn{2}{|c|}{$\begin{array}{l}\text { QC: WEB } \\
\text { Total Index }\end{array}$} & \multicolumn{2}{|c|}{$\begin{array}{l}\text { QC: } \text { CM } \\
\text { Total Index }\end{array}$} \\
\hline & 166 & 1.16 & 36 & 0.65 & 66 & 1.48 \\
\hline $\begin{array}{l}\text { FT11 ... help to manage the complexity of design projects with } \\
\text { variable. rich requirements. }\end{array}$ & 172 & 1.2 & 51 & 0.93 & 52 & 1.18 \\
\hline FT13 ... foster communication among project members. & 192 & 1.34 & 72 & 1.3 & 48 & 1.08 \\
\hline $\begin{array}{l}\text { FT19 ... make competencies accessible and useable for } \\
\text { organisations. }\end{array}$ & 146 & 1.06 & 66 & 1.2 & 66 & 1.48 \\
\hline $\begin{array}{r}\text { FT34 ... manage virtual teams in a dynamic environment that is } \\
\text { described by fluid boundaries and fluid team memberships. }\end{array}$ & 144 & 1.01 & 46 & 0.84 & 52 & 1.18 \\
\hline FC2 ... help to manage cross functional design projects. & 116 & 0.8 & 66 & 1.2 & 32 & 0.72 \\
\hline FC4 ... increase project member's satisfaction. & 120 & 0.84 & 48 & 0.87 & 45 & 1.02 \\
\hline FC17 $\ldots$ allow team leader animation. & 134 & 0.94 & 52 & 0.94 & 26 & 0.59 \\
\hline FC19 ... consider principles of risk management. & 142 & 0.99 & 38 & 0.69 & 38 & 0.86 \\
\hline FC24 $\ldots$ extract. produce and make knowledge accessible. & 126 & 0.88 & 60 & 1.09 & 29 & 0.66 \\
\hline $\begin{array}{l}\text { FC29 ... allow distance reduction and easy socialization in } \\
\text { trustworthy virtual environment. }\end{array}$ & 102 & 0.71 & 66 & 1.2 & 29 & 0.66 \\
\hline $\begin{array}{l}\text { FC35 ... generate and implement ideas. solutions and } \\
\text { improvements. }\end{array}$ & 157 & 1.1 & 60 & 1.09 & 64 & 0.66 \\
\hline$\varnothing$ & $\begin{array}{c}143 . \\
08\end{array}$ & 1 & $\begin{array}{l}55 . \\
08\end{array}$ & 1 & $\begin{array}{l}44 . \\
25\end{array}$ & 1 \\
\hline
\end{tabular}

Next to the simple additions of the total, indexes are calculated by division with the mean values to allow direct comparison. Table 2 is rich on information. We set the focus on the customer requirements. As example, we devote to the beforehand presented functions FT19 "The system should make competencies accessible and useable for organisations" and FC29 "The system should allow distance reduction and easy socialization in trustworthy virtual environment”. Regarding all quality characteristics of the four different domains (QC:all) FC29 shows an index of 0.71, while FT19 is better replied by this extract of concepts and techniques with an index of 1.06. Concentrating on how the respective quality characteristics of the web 2.0 tools (QC:WEB) respond to the demand shows for FT 19 an index of 1.2. The index of the quality characteristics of competence management (QC:CM) is 1.48. As function FT19 considers competencies as focus, it is evident that the QC:CM respond on the demand. Interestingly, also the QC:WEB satisfies its demand significantly which seems to be based on the access of competencies that provides web 2.0 tools.

In contrast, FC29 is well satisfied by QC:WEB (index: 1.2) but less by QC:CM (index: 0.66). Regarding the index of QC:all (0.71) highlights that the web 2.0 tools respond the best to this requirement.

\subsection{Results due to the Sample Survey}

In a second step we concentrate on the quality characteristics. That gives insights about the relationship matrix from another point of view. To give an example, we point on the respective QC:WEB considering also the beforehand presented sample survey to compare the theoretical results of this extract of the Aided VTB System with the industrial reality. The analysis of web 2.0 tools is shown in table 3 . 
Table 3. Valuing web 2.0 tools due to the house of quality and the sample survey

\begin{tabular}{|l|c|c|c|c|c|c|c|c|c|}
\hline House of Quality & Chat & Fm & Conf & Blog & Wiki & P.S. & C.P.R. & S.N. & $\varnothing$ \\
\hline $\begin{array}{l}\text { A. Relation to customer } \\
\text { requirements }\end{array}$ & 40 & 102 & 108 & 80 & 108 & 70 & 90 & 84 & 85.3 \\
\hline Index A & $\mathbf{0 . 4 7}$ & $\mathbf{1 . 2 0}$ & $\mathbf{1 . 2 7}$ & $\mathbf{0 . 9 4}$ & $\mathbf{1 . 2 7}$ & $\mathbf{0 . 8 2}$ & $\mathbf{1 . 0 6}$ & $\mathbf{0 . 9 9}$ & $\mathbf{1 . 0 0}$ \\
\hline $\begin{array}{l}\text { B. Correlation to the quality } \\
\text { characteristics of all three do- } \\
\text { mains: CM. VPM. VTB }\end{array}$ & 19 & 35 & 39 & 18 & 35 & 34 & 35 & 28 & 30.4 \\
\hline Index B & $\mathbf{0 . 6 3}$ & $\mathbf{1 . 1 5}$ & $\mathbf{1 . 2 8}$ & $\mathbf{0 . 5 9}$ & $\mathbf{1 . 1 5}$ & $\mathbf{1 . 1 2}$ & $\mathbf{1 . 1 5}$ & $\mathbf{0 . 9 2}$ & $\mathbf{1 . 0 0}$ \\
\hline $\begin{array}{l}\text { C. Correlation to the quality } \\
\text { characteristics of the domain CM }\end{array}$ & 3 & 10 & 10 & 7 & 11 & 7 & 12 & 11 & 8.9 \\
\hline Index C & $\mathbf{0 . 3 4}$ & $\mathbf{1 . 1 2}$ & $\mathbf{1 . 1 2}$ & $\mathbf{0 . 7 9}$ & $\mathbf{1 . 2 4}$ & $\mathbf{0 . 7 9}$ & $\mathbf{1 . 3 5}$ & $\mathbf{1 . 2 4}$ & $\mathbf{1 . 0 0}$ \\
\hline Sample Survey & & & & & & & & & \\
\hline \% of use in the sample survey & 1.38 & 0.83 & 1.20 & 0.53 & 0.43 & 1.49 & 0.88 & 1.26 & 1.00 \\
\hline Interest rate in the sample survey & 1.01 & 0.95 & 1.32 & 0.82 & 0.78 & 1.29 & 0.93 & 0.89 & 1.00 \\
\hline
\end{tabular}

Index A highlights how the concepts and techniques of the domain of web 2.0 tools answer to the need of the customer requirements. While the web 2.0 tools web conferencing (1.27) and wiki (1.27) satisfy the best the demand, chat (0.47) does hardly respond to the customer requirements.

Index B focuses on the correlation matrix of the house of quality. Blog (0.59) and chat (0.63) show the less correlation with the quality characteristics of the three other domains. Web conferencing (1.28) shows the highest correlation with the other quality characteristics. The correlation matrix is important to analyse which quality characteristics are compatible to provide the Aided VTB System.

Index $C$ presents the correlation between each respective web 2.0 tool and the quality characteristics in the domain of competence management. While chat $(0.34)$ shows again the less correlation commenting, rating, polling (1.35) show the highest one.

In the second part of table 3, the sample survey highlights that the web 2.0 tool chat (1.38 and 1.01) is overused compared to its actual use and its interest estimation. On the opposite, the web 2.0 tools blog $(0.53$ and 0.82$)$ wiki $(0.43$ and 0.78$)$ show an interest at a higher level than their actual use.

\section{Conclusion and Future Work}

Care must be taken in generalizing our results, however given the small sample survey size. The size of the sample survey and the extract of the Aided VTB System trigger an uncertainty level which has to be taken into account in our conclusions. More than to generalize the results of this study, we intended to represent our approach of the Aided VTB System to make future choices of web 2.0 tools based on a robust basis. We are aware that the small extract that we have given as example is not significant but it gives sophisticated insights of how the Aided VTB System may function in future. Nevertheless, we would like to give some recommendations due to our results.

- To implement an Aided VTB System quality characteristics which are in high correlation with forums and wikis should be fostered. For example "CM8 Repeatedly analysis of partial tasks to determine changed requirements for competencies during the process" that deepens the debate with structured and collective tools. 
- Virtual team leader should discourage the use of the chat as soon as team members' conversation deals with their project and encourage forum, wiki, commenting, pooling and rating. Those tools are under used and rated according to their respond to the demand of the customer requirements and the value provided by their correlation to the three other types of quality characteristics in the domain of competence management, virtual project management, and virtual team building.

- To respond to the demand of FC29 virtual team leaders could compensate the distance with "physical" meeting at specific occasions, particularly at project kick off meeting and in the end of phases.

- The quality characteristics in the domain of competence management have been presented as human dimension of the Aided VTB System. Interestingly, is that the web 2.0 tools respond also to human demands (FT19) and the correlation between some of the web 2.0 tools and the quality characteristics in the domain of competence management is much higher than expected. Future work should consider the human side of technical dimensions.

In future research we are concentrating on customer requirements that are not satisfied because there are solutions missing in the literature. In this case it will be purpose to propose concepts and techniques that answer as quality characteristics to the need of the customer requirements. Additionally, we aim to provide an interrogation platform in form of the house of quality where concepts and techniques of already welldeveloped methodologies could be consolidated. This permits us to be as inclusive as possible also in all four domains of competence management, virtual project management, virtual team building, and web 2.0 tools. The fast development of use web 2.0 tools and the regular arrival of new tools make necessary to reevaluate the use and the perceptions. The list of these tools increases quickly, so that the understanding and the choice of them becomes a managerial issue.

\section{References}

1. Horvarth, L., Tobin, T.J.: Twenty-first century teamwork: Defining competencies for virtual teams. Virtual teams 8, 239-258 (2001)

2. Picard, W.: Social Protocols for Agile Virtual Teams, PRO-VE 2009 - 10th IFIP - International Federation for Information Proceeding - Working Conference on Virtual Enterprises, Thessaloniki (October 2009); In: Luis M. Camarinha-Matos, Iraklis Paraskasis and Hamideh Afsarmanesh (Eds.) Levering Knowledge for Innovation in Collaborative Networks, pp. 169-178. Springer, Heidelberg (2009)

3. Griffith, T.L., Sawyer, J.E., Neale, M.A.: Virtualness and Knowledge in Teams: Managing the Love Triangle in Organizations, Individuals, and Information technology. MIS Quarterly (27), 265-287 (2003)

4. Schmidt, J.B., Montoya-Weiss, M.M., Massey, A.P.: New Product Development DecisionMaking Effectivness: Comparing Individuals, Face-To-Face Teams, and Virtual Teams. Decision Science 32(4), 575-601 (2001)

5. McDonough, E.F., Kahn, K.B., Barczak, G.: An investigation of the use of global, virtual, and colocated new product development team. Journal of Product Innovation Management 18(2), 110-120 (2001) 
6. Rezgui, Y.: Exploring virtual team-working effectiveness in the construction sector. Interacting with Computers (19), 96-112 (2007)

7. DiNucci, D.: Fragmented Future. Print 53(4), 2-32 (1999)

8. Schumacher, M., Stal-Le Cardinal, J., Mekhilef, M.: A competence management methodology for virtual teams - A systemic approach to support innovation processes in SME's. In: International Design Conference - Design 2008, Dubrovnik (2008)

9. Schumacher, M., Stal-Le Cardinal, J., Bocquet, J.C.: Towards a methodology for managing competencies in virtual teams - A systemic approach, PRO-VE 2009 - 10th IFIP - International Federation for Information Proceeding - Working Conference on Virtual Enterprises, Thessaloniki (October 2009); In: Luis M. Camarinha-Matos, Iraklis Paraskasis and Hamideh Afsarmanesh (Eds.) Levering Knowledge for Innovation in Collaborative Networks, pp. 235-244. Springer, Heidelberg (2009)

10. Akao, Y.: Quality Function Deployment. Productivity Press, Portland (1990)

11. Hauser, J., Clausing, D.: House of Quality. Harvard Business Review (2009)

12. Le Moigne, J.L.: La théorie du système général, Théorie de la modélisation. Presses Universitaires de France, Col. Systèmes-Décisions, Paris (1977)

13. Marion, J.T., Schumacher, M.: Moving New Venture New Product Development from Information Push to Pull Using Web 2.0. In: International Conference on Engineering Design, ICED 2009, Stanford (2009)

14. Edmondson, A.C., Nembhard, I.M.: Product Development and learning in Project Teams: The Challenges Are tge Benefits. Journal of Product Innovation Management (26), 123 138 (2009)

15. Kjellberg, A.: Teams- What's Next? From Fragmentation and Consciousness to Responsiveness by Competence Management for Modular Manufacturing Learning. Annals of the CIRP 48(2), 599-609 (1999)

16. Berio, G., Hazallah, M.: Towards an integrating architecture for competence management. Computer in Industry 58, 199-209 (2007)

17. Shpitalni, M., Guttmann, G., Bossin, D.: Creation of project teams in networks of excellence. In: 2nd German-Israeli Symposium on Design and Manufacture, Advances in Methods and Systems for the development of Products and Processes, Production Technology Center, Berlin, Germany, pp. 3-12. Fraunhofer IRB Verlag (2005) 